\title{
SOME EXPERIENCE FROM THE ANALYSIS OF EXISTING 40 YEARS OLD PRESTRESSED BRIDGES IN THE NORTH OF SLOVAKIA
}

The paper deals with the analysis of the chosen short-span bridges from precast prestressed concrete girders. The analysis has been performed at the Department of Structures and Bridges recently. Part of the current technical condition assessment of these structures comprised the load carrying capacity and remaining life time determined by calculation [1, 2 and 3]. The load carrying capacity was calculated in compliance with the previous Slovak standards and new European standards.

Keywords: Diagnostic, inspections, bridge, prestressed concrete, load carrying capacity, rehabilitation.

\section{Introduction}

In cooperation with the Slovak Road Administration, Investment and Construction Management of Roads (Zilina), diagnostic works were conducted on several existing precast prestressed bridges. In this paper, we pay attention to some characteristic features of those structures, e.g., to multi-element beam structures [4, 5 and 6]. The first bridge, No. 018-293 - see Fig. 1, is located on $\mathrm{I} / 18$ road and leads over the railway line, rural roads and the nameless creek near the town of Martin. The next one, No. 059-091 - see Fig. 2, is located on E77 road and crosses the river Orava. The third observed bridge, No. 065-086 - see Fig. 3, was built near the village Mosovce on I/65 main road, over the regional road. All the investigated bridges are around 40-50 years old. The main tasks were the assessment of current technical conditions and determination of load carrying capacity influenced by degradation factors due to environmental loading [7, 8 and 9]. On the base of the results gathered from assessment, we made decision in the form of a conceptual design with the aim to eliminate detected deteriorations, to improve the current conditions of the bridges and to increase the load carrying capacity and the serviceability of those bridges.

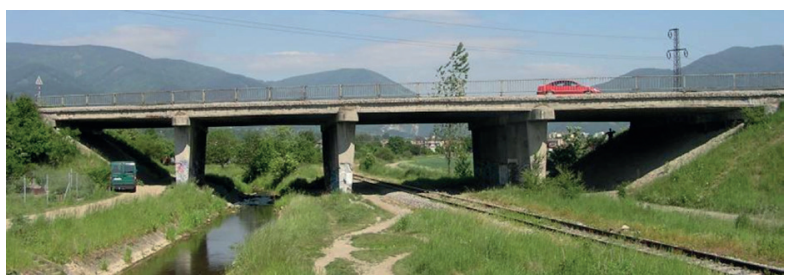

Fig. 1 The view of bridge No. 018-293 near the town of Martin on I/18 road
Based on the diagnostics and calculation of the current load carrying capacity of the mentioned bridges, it was decided to launch the project of their rehabilitation and structural strengthening.

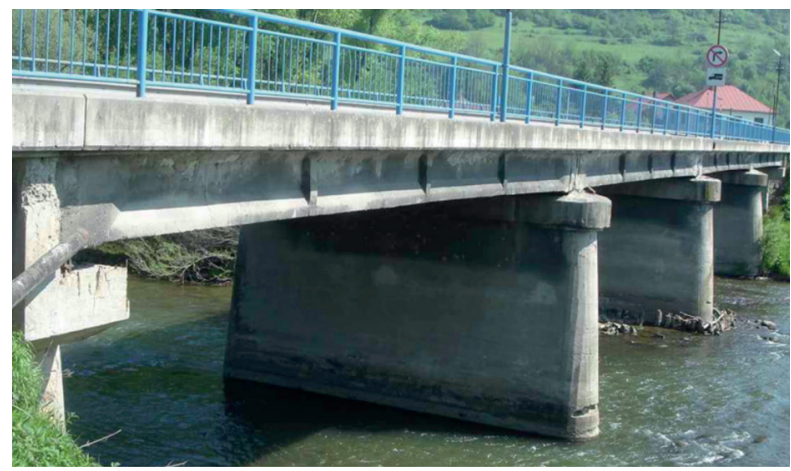

Fig. 2 The view of bridge No. 059-091 in Nizna over the river Orava

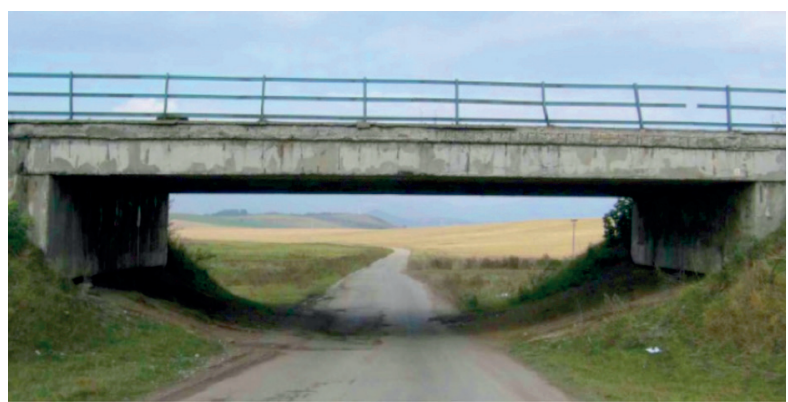

Fig. 3 The view of bridge No. 065-086 near the village Mosovce

\footnotetext{
* Martin Moravcik, Peter Kotes, Miroslav Brodnan, Patrik Kotula

Department of Structures and Bridges, Faculty of Civil Engineering, University of Zilina, Slovakia

E-mail: martin.moravcik@fstav.uniza.sk
} 


\section{The description of bridges}

The first bridge, No. 018-293, was built in 1964. That bridge crosses the nameless creek, railway line from Vrutky to Martin and two rural roads. The traffic on the railway line is currently not so heavy. Carriageway width on the bridge is $16.335 \mathrm{~m}$ with the both sides gadroon $2 \times 0.5 \mathrm{~m}$. The bridge consists of 4 simple spans, of post-tensioned concrete girders type of VLOSSAK of $14.40 \mathrm{~m}$. The spans are $2 \times 12.51+2 \times 12.91 \mathrm{~m}$. The total length of the bridge is $55.90 \mathrm{~m}$. Vlossak type beams are 0.98 meters wide, the construction height is $0.70 \mathrm{~m}$. The beams are made from the concrete $\mathrm{C} 45 / 55$ (B 600) and post-tensioned by the tendons from the smooth wires $f .5 \mathrm{~mm}$. The caps and 7 pieces of columns in cross-section were made as precast elements. They have a variable cross-section which changes along the longitudinal direction downward from $1.40 \mathrm{~m}$ to $0.90 \mathrm{~m}$ near the ground. The column width is constant $-0.25 \mathrm{~m}$. At the time when the bridge was designed, such solutions with non-dilatation contact joints over the internal supports were not common.

The second bridge, No. 059-091, was built in 1957 on the site of a previous steel bridge with the lower deck, suspended on two parabolic curves of the range of $2 \times 35 \mathrm{~m}$. It was destroyed during World War II. The substructure, two abutments and one pier remained preserved. A wooden temporary bridge was built on the site of the original bridge. In the center of the original spans wooden barges were built. The newly built 4-span bridge had a range of one span from 16 to $17 \mathrm{~m}$. The bridge was not insulated against water, which adversely affected the superstructure. Currently, the superstructure in cross-section consists of 10 post-tensioned atypical precast girders of „," shape. In the longitudinal section, beams act as 4 simple separate spans, each with a range of $17.175 \mathrm{~m}$ and a beam length of $17.875 \mathrm{~m}$ with spacing over a support from 20 to $40 \mathrm{~mm}$. The total projected length of the superstructure is $71.64 \mathrm{~m}$. In the longitudinal direction, the beams are not connected. Five cross beams act in the transverse direction. The joints between the beams with a width of about $50 \mathrm{~mm}$ are embedded in cement mortar. The superstructure was prestressed by the cross prestressing tendons from the 9 wires of $f 4.5 \mathrm{~mm}$. The tendons were placed in the top flange of the beam and in the bottom of the transverse beams.

The third mentioned bridge, No. 065-086, was built in 1972 near the village Mosovce. It is a one span bridge crossing the regional road with $16.0 \mathrm{~m}$ long span. The superstructure in cross-section consists of 12 post-tensioned precast girders of the type KA- 61 of a box shape with the total length of $15.0 \mathrm{~m}$. The transverse structural behavior acts as a "curtain" slab. The KA-61 girder has a construction width of $0.98 \mathrm{~m}$ and height of $0.70 \mathrm{~m}$. The girder was prestressed by 6 tendons from 12 wires of $f .5 \mathrm{~mm}$ and 2 tendons from 6 wires of $f 4.5 \mathrm{~mm}$. The tendons are placed at the bottom slab and webs parts of the beam. The girders are made from the concrete C35/45 (B 500).

\section{The current technical conditions of bridges}

Failures, which have been observed on bridge 018-293, result both from the state of knowledge about bridge building accessible at the time when the bridge was built and also from insufficient maintenance at present. Outer girders, connection joints between the girders and over-supporting parts of the beams are the mostly damaged parts of the superstructure. On outer girders we can see uncovered, exposed, corroded tendons with some ruptured wires. Similar situation can be seen also in Figs. 4 and 5. Loss of cement mortar can be seen mainly in the peripheral connection joints and in over-supporting areas as a result of water leakage through these joints. Precast girders carry all typical features of the first prestressed concrete bridges built in Slovakia. The areas and the edges are rough and broken, the visible surfaces are marked with water leaking through the carriageway and insulation on the superstructure.

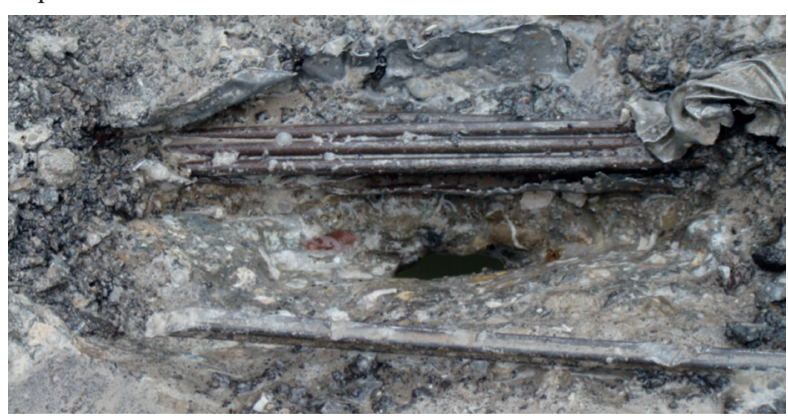

Fig. 4 The partial rupture of wires of the prestressing tendon - bridge No. 059-091

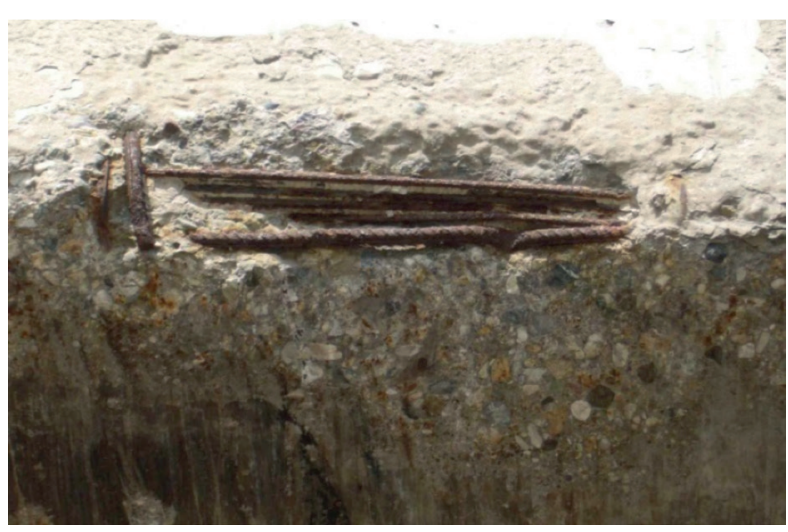

Fig. 5 The partial rupture of wires of the prestressing tendon - bridge No. 065-086

The precast superstructure of bridge No. 059-091 carries all the signs of such bridges from the 1st generation of prestressed structures in Slovakia. Consequences of water leakage through the carriageway and insulation can be seen on the superstructure. Anchored areas of the superstructure cross prestressing, particularly in over-supporting sections carry the signs of failures 
due to leakage as, for example, removed concrete cover, and corroded anchors. However, the structural system realized in this way is still relatively solid. The girders in the longitudinal direction have still sufficient pressure reserve, which is noticeable in the overhanding. There are some major defects due to technical difficulties connected with cross prestressing and separate spans without linking the neighboring spans by a composite slab.

One of the main deficiencies of the precast superstructure of bridge No. 065-086 from the KA-61 girders is a box shape of the designed girder. The closed shape of the girder cross-section causes the wet environment inside the girder, which affects the rapid reinforcement corrosion. That effect can be seen on many bridges constructed from the KA- 61 girders.

\section{The results of the diagnostic works}

It was found out that the strength of concrete on bridge No. 018-293 corresponds to concrete class $\mathrm{C} 25 / 30$ according to [10], or to concrete class B 330 according to the previous Slovak standard. Strength of concrete was tested in a non-destructive way with the Schmidt hammer type L. Content of chloride ions, especially in the concrete cover, was determined by the tests of RCT instrument. The carbonation depth was determined by a simple indication method by spreading the concrete with phenolphthalein. On the exposed areas of reinforcement incurred by the fall of the concrete cover, the corrosion of prestressed reinforcement was found leading to the rupture of some wires.

On the basis of inspections, the bridge classification according to [11] was replaced by [12] as follows: - The bridge top cover condition: $\mathrm{V} .=$ bad, the substructure condition: IV.$=$ satisfactory, the superstructure condition: VI. = very bad, complex bridge condition: $\mathrm{V}$. = bad.

It was found out that the strength of concrete of the precast beams on bridge No. 059-091 was C30/37 (B 400), which corresponds to the designed value. Content of chloride ions $\mathrm{Cl}-1$ mc was above the critical value (Fig. 6). The carbonation depth was lower than the concrete cover (Fig. 7). Technical condition

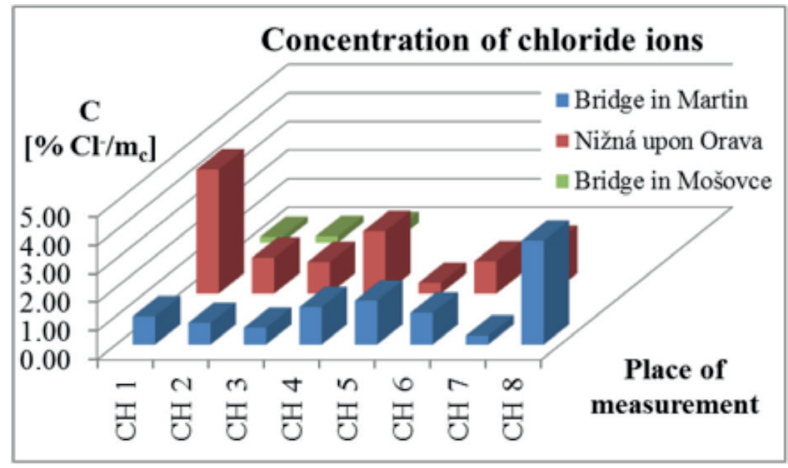

Fig. 6 The concentration of chloride ions- overview of the bridge, according to [11 and 12] and by visual inspection, can be evaluated as follows:

- The bridge top cover condition: IV. = satisfactory $-\mathrm{V} .=$ bad, the substructure condition: V. = bad, the superstructure condition: III. = good - IV. satisfactory, complex bridge condition: $\mathrm{V}$. = bad.

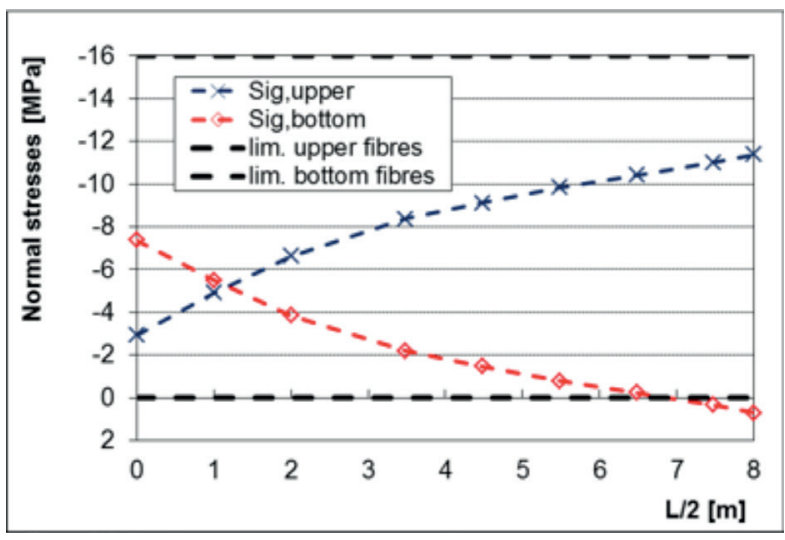

Fig. 7 The carbonation depth - overview

The load carrying capacity showed the following results: $\mathrm{Vn}=20$ tons $(62,5 \%$ of required standard value $), \mathrm{Vr}=34$ tons, $(42,5 \%$ of required standard value) $\mathrm{Ve}=77$ tons $(39,3 \%$ of required standard value), which indicates the insufficient structural capacity. ( $\mathrm{Vn}$ is the normal load carrying capacity, $\mathrm{Vr}$ is the exclusive load carrying capacity and $\mathrm{Ve}$ is the exceptional load carrying capacity).

It was found out that the strength of concrete of the precast beams on bridge No. 065-086 was C35/45 (B 500), which corresponds to the designed value similarly as with the above mentioned bridges. Content of chloride ions $\mathrm{Cl}-/ \mathrm{mc}$ exceeds the critical value of content of chloride ions Cl- (Fig. 6). The carbonation depth did not reach the value of the concrete cover

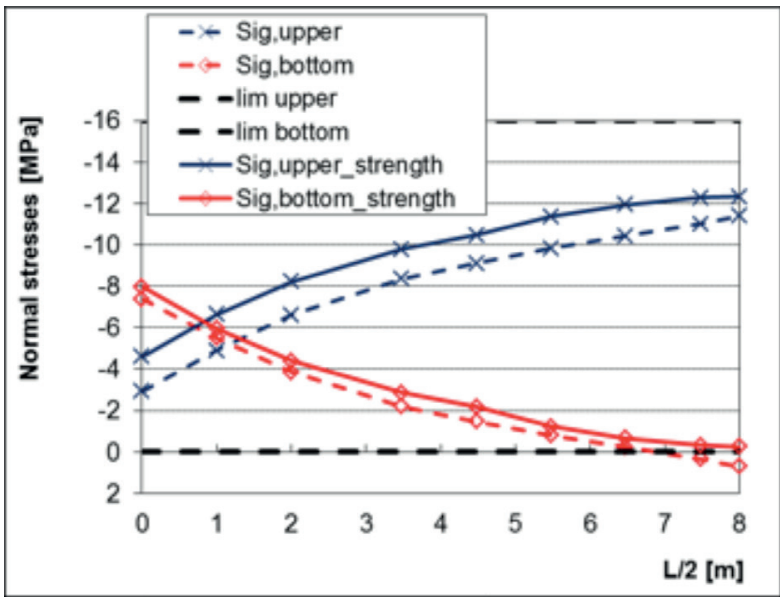

Fig. 8 The normal stresses course along the half span of bridge No. 065-086 
(Fig. 7). Technical condition of the bridge, according to [11 and 12] and by visual inspection, can be evaluated as follows:

- The bridge top cover condition: $\mathrm{V}$. = bad, the substructure condition: IV. = satisfactory, the superstructure condition: $\mathrm{V}$. = bad, complex bridge condition: $\mathrm{V}$. = bad. The load carrying capacity calculation showed the following results: $\mathrm{Vn}=25$ tons, $\mathrm{Vr}=59$ tons, $\mathrm{Ve}=183$ tons, which again indicates the insufficient structural capacity, see Fig. 8.

\section{Conception design of the bridges rehabilitation}

In the case of bridge No. 018-293 it is expected that the reconstruction work will be done with traffic moved over one lane of the bridge. Due to corrosion and subsequent rupture of prestressing tendons of outer girders it was proposed to remove them and replace them with new ones. Increasing the load carrying capacity should be achieved also by new composite slab concreting. The corroded caps have to be strengthened also in several possible ways, for example, by additional prestressing, or by other new reinforcement on the metallic or non-metallic base (FRP materials).

To determine the response of the bearing capacity of bridge No. 059-091, superstructure of the numerical model was used, taking into account the way of creating the connection of additionally prestressed precast beams " $\mathrm{T}$ " in the transverse direction. From the diagnostic survey, it was found that in some places the grout between the beams was broken, and, therefore, there may be rotation of the beam; cross prestress in the model can thus be considered semi-solid.

Despite the high age of the bridge and history of the Orava river bridged in this place, it was recommended to repair this bridge in order to increase its lifetime, and, at the same time, to maintain such capacity which corresponds to the current trends in designing new bridges. We suggest to repair the bridge superstructure by new external prestressing and new composite concrete slab.

In the case of bridge No. 065-086, the numerical model of the "curtain" slab was taken into account. The combination of the strengthening method was used due to the insufficient load carrying capacity. At first, all existing deteriorated elements will be removed from the top of the bridge. The new external prestressing ( 2 Monostrand tendons on 1 girder) was designed. Then new $150 \mathrm{~mm}$ depth of the composite slab concreting on the top of the girders is assumed to be applied. That kind of the structural invasion completely changes behavior of the superstructure from a "curtain" slab to the solid orthotropic slab (Fig. 9). The superstructure being strengthened, similar repair work will be conducted as in the above mentioned cases.

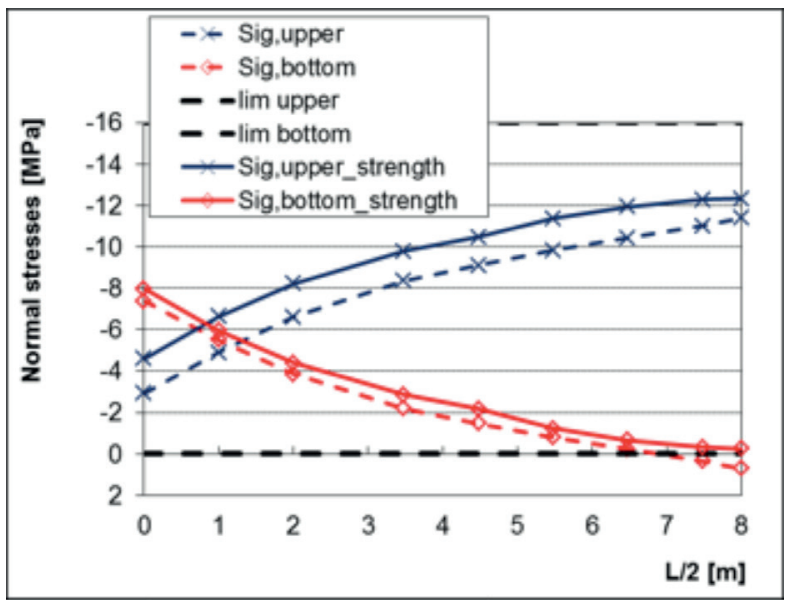

Fig. 9 The course of normal stresses along the half span on strengthened structure of bridge No. 065-086

\section{Conclusions}

Diagnostics and the load carrying capacity calculations showed that the chosen inspected prestressed concrete bridges built in Slovakia are generally in bad technical conditions after 40 - 50 years of service. It is mostly due to the improper conceptual design at that time and insufficient knowledge about structural behavior, construction detailing and building technology. Another reason of poor technical conditions of the bridges is their insufficient maintenance. But these bridges can be repaired using the modern methods and materials to the level which is required by the current European standards and regulations. The new composite slab concreting, external prestressing or adhesive FRP material base application are examples some methods frequently used for the strengthening of prestressed bridge structures.

This is demonstrated by the example of bridge No. 065-086 where repair work has been successfully done recently. Composite slab concreting and the external prestressing combination method were used for the structural strengthening, as shown in Fig. 10.

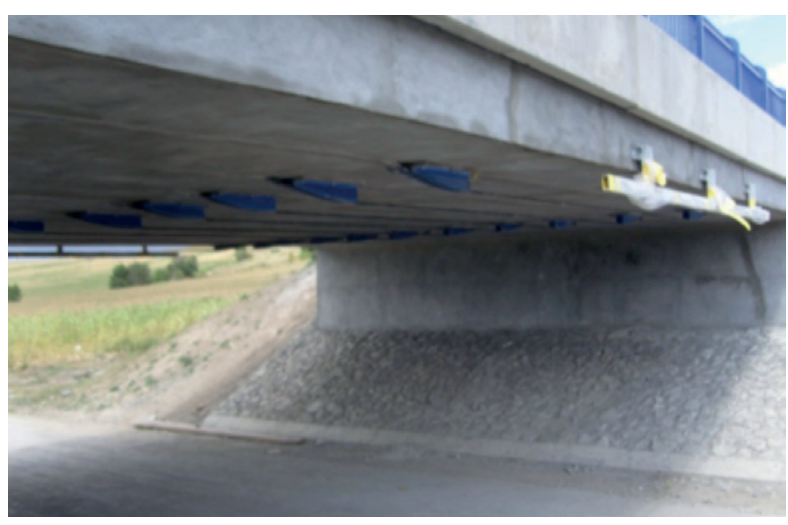

Fig. 10 Bridge No. 065-086 after strengthening by external prestressing 


\section{Acknowledgement}

The research work presented in this paper has been supported by the Slovak Grant Agency VEGA No. 1/0517/12 and supported by the European regional development fund and Slovak state budget by the project "Research centre of University of Zilina", ITMS 26220220183

\section{References}

[1] VICAN, J., GOCAL, J., MELIS, B., KOTES, P., KOTULA, P.: Real Behaviour and Remaining Lifetime of Bridge Structures. Communications - Scientific Letters of the University of Zilina, vol. 2, 2008, 30-37. ISSN 1335-4205.

[2] HALVONIK, J., BORZOVIC, V., DOLNAK, J.: Experience with Design of Prestressed Concrete Bridges According to Eurocode. Design of concrete structures using EN 1992-1-1: First Inter. Workshop, September 2010. Prague: Czech Technical University, 61-71. ISBN 978-80-01-04581-7.

[3] MORAVCIK, M., BUJNAKOVA, P.: New Precast Bridge Girder with Combined Prestressing. Communications - Scientific Letters of University of Zilina, vol. 13, No. 3, 2011, 19-23, ISSN 1335-4205.

[4] KOTES, P., VICAN, J.: Multi-element System Reliability using Markov Chain Model. Communications - Scientific Letters of the University of Zilina, vol. 3, 2004, 17-21. ISSN 1335-4205.

[5] BUJNAK, J., ODROBINAK, J.: Behaviour of Steel-concrete Composite Girder. Communications - Scientific Letters of the University of Zilina, vol. 5, No. 3, 2003, 48-49. ISSN 1335-4205.

[6] BUJNAK, J., HLINKA, R., ODROBINAK, J., VICAN, J.: Diagnostics and Evaluation of Footbridges. Procedia Engineering, vol. 40, 2012, 56-61. ISSN 1877-7058. On-line: http://ac.els-cdn.com/S1877705812024411/1-s2.0-S1877705812024411-main. pdf?_tid= c643ad4e-3482-11e2-8278-00000aab0f26\&acdnat=1353574885_b8932ef08b99b234bfc 77d9dbedb0393

[7] KOTES, P., VICAN, J., SLAVIK, J.: Influence of Reinforcement Corrosion on Reliability of Existing Concrete Structures. Communications - Scientific Letters of the University of Zilina, vol. 4, 2001, 41-49. ISSN 1335-4205.

[8] VICAN, J., KOTES, P., SLAVIK, J.: Effect of Degradation Factors on Existing Bridge Reliability. Communications - Scientific Letters of the University of Zilina, vol. 3, 2003, 62-63.

[9] GAJDOSOVA, K.: Stress and Crack Width Control According to EN 1992. Proc. of intern. workshop Design of concrete structures using Eurocodes, September, 2012. Technische Universitat: Wien, 2012, ISBN 978-3-902749-03-1, 199-202.

[10] STN EN 206-1 Concrete, Part 1: Specification, Performance, Production and Conformity, SUTN Bratislava, 2002.

[11] TP 04/2008: Load Carrying Capacity of Bridges on Expressways, Highways, Roads of 1st, 2nd, and 3rd Category and Local Roads + Annexes A, B (in Slovak). SSC Bratislava, 2008.

[12] Guidance USM 1/2012: Load Carrying Capacity of Bridges (in Slovak). SSC Bratislava, 2012. 